\title{
Technological progress and the future of the corporation
}

\author{
ASSAF HAMDANI, NIRON HASHAI, \\ EUGENE KANDEL and YISHAY YAFEH
}

Abstract: Drastic and rapid technological changes, driven by the ability to process large data at unprecedented speed and the use of algorithms to make decisions, drastically change the way corporations do business. Disruptive innovation originates from outside of traditional industries, as data are accessible and distribution inexpensive. Giant online platforms gather vast amounts of data from users and control access to them. They invest massively in research, threatening more industries. These rapid changes challenge regulators, especially vis-à-vis technology giants. This chapter outlines the effects of technology on corporate governance, contracting, labour productivity, efficiency, and market transactions. It concludes that drastic changes in the corporate form are not likely, but that there is likely to be much change in how corporations are run.

Keywords: Disruptive technologies, online platforms, corporate form, corporate behaviour.

\section{EXECUTIVE SUMMARY}

The evolution of the corporation, its ownership and structure have followed major business, market, and legal developments, including the antitrust legislation in the United States in the late 19th century, the dissolution of corporate pyramids in the 1930s and 1940s, and the unravelling of diversified conglomerates in the 1960s to the 1980 s.

Throughout, however, the basic structure of the corporation has remained the same. Today, many corporations are threatened by disruptive technological changes, while technology giants seem to grow stronger, threatening many industries.

These changes have become more drastic, driven by the ability to rapidly collect and process vast amounts of data and then combine them with artificial intelligence (AI) to make smarter decisions. Data and knowledge have dispersed away from large 
corporations, undermining their traditional advantages, and the cost of digital innovation has dramatically declined. At the same time, online platforms gather data from users over whom they have considerable control, and analyse and use the information to dramatically affect consumer and producer decisions. Regulators, meanwhile, struggle to keep pace with these trends.

The structure and governance of future corporations are very likely to be impacted by technological changes as competitive threats, but also by technologically improved contracts, increased labour productivity along with some labour replacement (by robots), improved organisational efficiency, and the technologically increased ease of market transactions.

Traditionally, novel technologies have been developed in house (within companies), but increasingly corporations are collaborating with outsiders, altering organisational structures and the ways in which business is done. New hybrid forms of the corporation, such as public benefit firms, are evolving, albeit still on a very small scale. Technological developments might facilitate these forms (reducing agency costs, for example), but the basic legal construct of the corporation is likely to remain unchanged.

Using a 'nexus of contracts' framework, this paper identifies some technologies which are likely to disrupt large businesses in the next decade and describes their possible effects on corporations. Examples of technologies which are significant in this respect include big data/AI, blockchain, and smart contracts, computer vision, quantum computing, and 3D printing. These technologies are different from innovations of the past in that they substitute for human senses and brains, rather than muscles. Sophisticated algorithms are already performing more consistently, more fairly, and more accurately than humans in some domains. Many technologies are also set to replace and reallocate labour, with significant social implications.

The rate of technological change appears to be intensifying over time and is perhaps becoming less predictable. Most economic models suggest that there is no real threat to the corporation as the entity of choice for organising economic activity. But is the current wave of disruptive technology qualitatively different? The paper suggests the hazard that well-known economic models may be missing is the possibility of 'cataclysmic' events provoking political responses which could endanger the future of the corporation.

Aside from the nature, pace, and effects of technological changes on the structure and purpose of the corporation, the paper also addresses several possible sociopolitical effects, including upheaval in labour markets and further increase in inequality, leading to a bifurcated economy, where small atomistic companies coexist with giant companies that become increasingly distrusted by the public and governments, as happened numerous times in the past. 
The authors also discuss the potential effect of technology on corporate governance. New technologies can significantly reduce the cost of monitoring agents (managers) by principals (shareholders and regulators), which may have far-reaching implications for both the corporate governance and the regulation of public corporations. The two main features which may be affected by new technologies are the ability to monitor agents and the ability to process information in order to make better predictions. Executive compensation, for example, can be determined by smart contracts that are set in advance and require no ex post discretion. AI algorithms also can replace human analysts struggling with huge amounts of corporate disclosures.

The paper also draws parallels between today's tech giants and the companies that dominated the US economy in the late 19th century. As in the late 19th century, the perception today is that existing regulatory tools are inadequate or insufficient to contain the rising power of these tech giants. Political pressures might lead to a new set of regulatory tools, perhaps even coordinated across borders, to deal with the power of present-day tech giants. The challenge is to prepare the conceptual basis on how these tools must work so as to prevent abuse while at the same time not impeding technological progress.

\section{INTRODUCTION}

The evolution of the corporation, its ownership and structure have followed major business, market, and legal developments. Examples from the United States include antitrust legislation in the late 19th and early 20th century in response to the formation of voting trusts; the dissolution of corporate pyramids in the 1930s and 1940s by legislation targetting public utilities and other business groups; the evolution and unravelling of diversified conglomerates between the 1960s and the 1980s, and the rise of director independence and the monitoring board following regulatory measures, such as the Foreign Corrupt Practices and Sarbanes-Oxley Acts. Similar changes have taken place in other countries (for example, Japan, Korea, and Israel). These developments affected ownership structures, corporate governance, and market interactions between companies, challenging the notion of the goals of the corporation. Throughout these changes, however, the basic structure of the corporation has remained the same.

Corporations today find themselves threatened by disruptive technological changes that jeopardise the very existence of some companies, while forcing others to adopt new technologies and business practices to join the revolution rather than be buried by it. In contrast, technology giants - some of them newcomers - seem to grow stronger every year, threatening many industries. 
Technological changes have become more drastic and rapid over the last few decades, increasingly driven by the ability to collect and process enormous amounts of data at unprecedented speed, combined with the ability to use artificial intelligence (AI) to make smarter decisions. This has led to two contradictory developments. On the one hand, more and more of the data-driven disruptive innovation is done outside of large corporations for two reasons. First, data and knowledge have become more dispersed and much is in the public domain, allegedly reducing the traditional advantage of large companies. Second, as software is increasingly replacing hardware, the cost of digital innovation and of distributing the resulting products has dramatically declined due to cloud computing and better consumer targetting, allowing relatively small initial investments to yield potentially large pay-offs. As a result, popular online platforms increasingly control vast amounts of valuable data, which they gather from their users. The corporate owners of these platforms enjoy a substantial advantage in data and control over access to their customers. These giants invest in research in areas such as robotics, autonomous vehicles, AI, and computer vision at such a scale that in some cases it surpasses the best universities. Finally, the industry is changing the landscape so rapidly that regulators are very much behind in dealing with technology giants.

What could be the effect of these technological changes on the future of corporations? At this stage, we can identify several major developments with potential effects on firms' structure and their governance: the expansion of competitive threats, technologically improved contracts, increased labour productivity combined with some labour replacement, improved organisational efficiency, and the increased ease of market transactions. Some of these have opposing effects on the size and scope of corporate activities, so the task of predicting their impact is rather difficult.

Technological change significantly expands the universe of competitive threats. A decade ago, a large insurance company faced competition from other large insurance companies, while today it also faces competition from large and small firms that are not even in the insurance industry, yet are working on ways to make the traditional insurance model obsolete. The fate of Kodak, Nokia, and many others shows that large companies are not immune to disruptions and existential threats; they must embrace rapid technological changes to survive. Consequently, many large established corporations are increasingly open to alternative forms of innovation that require extensive collaboration with outsiders and may considerably alter both the way they do business and their organisational structure. This is contrary to the traditional approach, in which novel core technologies were typically developed in house.

The core features of the corporate form-legal personality, limited liability, transferable shares - have survived a couple of centuries of dramatic market and technological changes. One should be cautious in making predictions about the impact 
of new technological developments on these fundamental building blocks of the corporate form, whose features are so basic and robust that they can support a wide spectrum of business organisations, ranging from private firms with a handful of shareholders to multinational corporations with dispersed ownership. Nevertheless, there are new initiatives to create hybrid forms of corporations - such as the public benefit corporation (that aims at maximising both profits and predefined social goals). Technological developments might facilitate the evolution of these hybrid corporate forms (to the extent that they reduce agency costs, for example), while remaining within the same legal construct.

Moreover, while there is little evidence that rapid technological change will alter the structure of the corporation, it is clear that it is likely to change the ways companies are run and their internal incentive systems. Google, Amazon, and Facebook are corporations, just like Coca-Cola and General Motors: they have the same legal structure, but in fact operate very differently, both internally and externally. Thus the main focus in this paper is on the technology-driven changes within the corporation, as well as in the market surrounding it, rather than changes in the very nature of the corporate form.

In what follows, we first identify the technologies that are likely to significantly disrupt large businesses in the next decade. Then we discuss their effect on corporations, using the 'nexus of contracts' framework. This discussion is followed by a brief overview of additional issues and tentative conclusions. We end every sub-section with several topics that would be of interest to research to address the issues raised in that section.

\section{CULPRITS: NEW TECHNOLOGIES AND THEIR POSSIBLE EFFECTS}

Prior to discussing the effect of the emerging technologies on the corporation, one must inquire as to why this issue is so relevant now and not, say, thirty years ago. New technologies have been appearing at an ever-rising rate for the last hundred years. What is different today?

A short list of technologies below, each individually and together, has the potential to disrupt the ways in which companies hire and deploy labour, reduce the cost of doing business (possibly by changing the nature of contracts), and improve firm access to customers. We present only the seemingly most disruptive technologies and their possible impact; additional ones can be added to the list:

Big datalmachine learning/NLP/AI - possible effects could include fewer, more productive workers more efficiently deployed, better corporate governance and control, allowing more decentralised corporate structures, better 
contracting in the market leading to lower transaction costs, higher trust, lower customer acquisition costs, more efficient market design, etc. (e.g., Agarwal et al. 2018, Furman \& Seamans 2018, Milgrom \& Tadelis, 2018).

2. Blockchain and smart contracts - simpler contracting, lower transaction (including agency) costs, reduced fraud, new business models for many businesses, possibly a substitute for missing legal institutions in emerging markets.

3. Computer vision - reduction in the number of low-skilled workers, less fraud.

4. Drones/autonomous vehicles - fewer workers, more efficient logistics.

5. Quantum computing - who knows?

6. $3 D$ printing - customisation of manufacturing, ease of design, fewer workers.

Do these technological changes differ from many others in the past to necessitate raising such existential questions? We identify several reasons why they may be qualitatively different:

1. For several thousand years, new technology substituted for human muscles: horses, ploughs, wind, water, steam, and electric energy, and the machines they powered. In the last few decades it is increasingly substituting for human senses and brains, mostly using software: that is, replacing skilled and knowledge workers, and the trend is only intensifying with the advent of the above-mentioned technologies and the increasing power of software. Computer vision, natural language processing, and audio capabilities, combined with rapid data processing and $\mathrm{AI}$, imply that any process of accumulating information, processing it in a predictable manner, and making relative routine decisions - what most white-collar workers actually do-may soon be performed by a computer. Sophisticated tasks, such as medical diagnosis, preparation of legal documents, and even programming are already being done by algorithms. Google, for instance, claims to have an automated capability to perform auditing tasks in a shorter time and with fewer mistakes than human accountants. Russian Sberbank already relies on AI to make loan decisions in 35 per cent of cases, anticipating that this will increase to 70 per cent in less than five years; many online platforms do that with all applications. 'Robot lawyers' have already substituted for 3,000 jobs in Sberbank's legal department (World Bank 2018).

2. As a result, new technologies have contributed to a vast change in the sectoral composition of employment in the world (especially in the last hundred years): a dramatic decline in the share of the labour force employed in agriculture and, over the last forty years, a significant decline in the share of manufacturing as well. Only the service sector has grown to almost 80 per 
cent of GDP in some countries. The current technological boom is mostly disrupting services, and, as a return to agricultural employment or even manufacturing is unlikely, most of the disruption and reallocation of labour will happen within the services sector, where many large corporations operate today.

3. The rate of technological change appears to be intensifying over time and is potentially becoming less predictable. Corporations are forced to operate in a much more uncertain and rapidly changing environment and may therefore require significant changes in their operational mode to adapt. In some sense, they have to learn to live in a constant disequilibrium. Gartner, the leading technology consulting firm, promotes a concept of 'Bimodal IT' to describe the conflicting forces applied on corporations due to digitalisation, which have to simultaneously be in two modes: Mode 1 is focussed on the predictability of better understood areas of their activity as they pertain to the current state of digitisation; Mode 2 is focussed on exploration and optimisation in areas of high uncertainty; corporations are forced to adapt to the current state of digitisation to become more efficient, while at the same time constantly exploring new business models. While these forces have always been in play, the rapid pace of technological evolution, and of the emergence of competing business models as a result, creates a qualitatively new environment. As a consequence, we see, for example, large companies making massive lay-offs and engaging in massive hiring at the same time. This is a very difficult task for a corporation, as large organisations usually do not cope well with uncertainty.

4. In the past, replacing someone's muscles by a machine required significant upfront capital investment. To replace more people, more machines had to be installed. Such substitution led to an increasing marginal product of labour and a decline in the marginal product of capital. Thus, there existed a reasonable reservation wage below which such replacement was no longer profitable. In many industries, this was the internal brake to a massive replacement of workers (Acemoglu \& Restrepo 2018, Zeira 1998), while in others, such as agriculture, the replacement was almost total. This time, most of the current and predicted disruptions are driven by the new-found ability to rapidly generate enormous amounts of data and process it. These processes are characterised by extreme economies of scale; so once the innovation takes place, the marginal cost of deploying it widely is rather small. This implies that the reservation wage below which it does not make sense to replace labour with new technologies is rapidly going to levels where a worker can no longer sustain herself (for example, below the minimum wage). This eliminates the embedded limit on the effect of technology adoption on unemployment and 
may cause a massive drop in the demand for labour, bringing about significant social unrest, which could eventually lead to dramatic changes in the organisation of economic activity. Even firms producing tangible products in industries that have been considered labour intensive (for example, plastic and textiles) can now use computers, localised robots, or 3D printers for many of their operations, necessitating fewer and fewer workers. The potential elimination of drivers of various types of vehicles is another example.

How should these and other features of new technologies, and the pace of their arrival, be reflected in theoretical models dealing with economic growth, employment, and wage evolution within the modern political economy? The recent literature in economics on these issues takes a neoclassical view on the organisation of economic activity and the results so far do not suggest a need to change this approach. Most models generate predictions that are only 'marginally' different from the historical effects of technology on the market, suggesting that there is no real threat to the corporation as the entity of choice for organising economic activity. The question is whether the current wave of disruptive technologies is qualitatively different, therefore requiring models that can generate drastically different outcomes-for example, massive unemployment and/or very low wages for unskilled workers. If reasonable models do not generate such outcomes, we can be relatively certain that the current corporate form will continue to dominate the economic landscape. It would be problematic, however, if conventional economic models missed the possibility for such a cataclysmic turn of events, as such dramatic changes may generate enough political will to fundamentally change (not necessarily for the better) the corporate structure. That is where, in our opinion, the main danger to the future of the corporation, or even capitalism, lies.

Consider modifying the widely used Zeira (1998) model of growth and labour. Assume that only a small percentage of the population can produce capital (for example, program AI algorithms or build robots). Also assume very significant economies of scale in the automation of certain tasks. The rest of the model is kept the same-over time, more tasks are performed by machines and computers, substituting for labour. Is there a plausible equilibrium with a large proportion of redundant labour force? What if most of the population is not employed and thus can afford only the basic consumption bundle? In such a case, is it conceivable that there will not be sufficient income growth to generate additional jobs? A recent study (Nakamura \& Zeira 2018) reaches the opposite conclusion: while automation can generate unemployment in the short run, in the long run unemployment will converge to zero. This analysis, however, does not assume economies of scale, and therefore the question remains open. 
Related to the previous point, today one can quite easily and inexpensively procure labour services in a variety of fields from any place in the world. Crowdsourcing provides reasonable quality assurance and low prices make experimentation feasible. The question is whether labour relations in the developed world can accommodate the emergence of fierce competition from abroad through the very short contracts that are already becoming prevalent. Will countries accept that or try to fight such contracts? Does it mean that, if countries do not accept such a shift, they are in danger of losing their most productive workers? What can we learn from Japanese human resource management practices since the 1950s, where a core of workers enjoyed tenure, high salary, and other privileges, while others working next to them had very few rights (see Kandel \& Pearson 2001)? The inability to change these contracts fast enough was allegedly (at least in part) responsible for the long stagnation period of the Japanese economy.

\section{Research questions—basic evidence on the impact of new technologies}

Most of the research questions pertaining to the impact of new technologies on the corporation are empirical in nature. Some important questions include:

- What is the degree of economies of scale of new technologies in comparison with more traditional ones?

- What is the rate of technological change in comparison with the last 150 years (oil, electricity, radio and telephone etc.)?

- Are the effects of AI and other technologies on manufacturing and services different from those of earlier technologies?

- What would be the predictions of the Zeira (1998) model with significant economies of scale?

\section{SOME PERSPECTIVES ON FIRM BOUNDARIES AND CORPORATE GOVERNANCE}

The legal and the economic literatures commonly conceptualise the corporation as a nexus of contracts. These contracts can be classified into several groups: contracts between entrepreneurs/managers and the suppliers of capital (both debt and equity); governance contracts; contracts between the firm and its employees; as well as contracts with consumers and suppliers. The ease and the cost of designing and enforcing contracts determine the transaction costs of doing business inside and outside the firm. In the context of Coase (1937) and Williamson (1975), significant changes in transaction costs are likely to change the boundaries of the firm. 
Many of these contracts are, or will be, affected by the technologies above. On the one hand, the rapid rise in computing power and the ability to accumulate vast amounts of data have facilitated seamless and fast connectivity among large numbers of atomistic players, thereby drastically reducing the costs of market-based transactions, creating many new marketplaces in the process. Examples include Airbnb, Lemonade, and Uber. In addition, blockchain technology allows identification and authentication at levels and scales previously unattainable, thus enabling a variety of inexpensive and easily enforceable contracts in almost any area. This could have a drastic effect on the corporate structure by moving many contracts and transactions outside the corporation and into the market. As a result, firms using traditional transactional methods (for example, retailers, intermediaries, asset managers, professional services firms, etc.), are likely to shrink, as the online market takes over some of their activities.

At the same time, some of these technologies improve labour productivity and reduce the required numbers of employees, as well as upgrading governance and contract enforcement within the corporations, thus reducing internal transaction costs within the corporation. Bloom et al. (2014) argue that various technologies may have opposing effects on the internal functioning of the corporation. Using a large data set, they find empirically that information technologies (for example, ERP and $\mathrm{CAD} / \mathrm{CAM}$ ) are associated with more autonomy given to remote plant managers and workers, while communication technologies (for example, intranets) have the opposite effect. Both are used to reduce the inherent frictions associated with running a multi-location large firm. Similarly, some new technologies may utilise internal data more efficiently to make better decisions and improve coordination. The net effect on the size and scope of the firm is, therefore, case-specific.

Banking presents an interesting test case. A fascinating question is whether banks (and other financial institutions) will be replaced by independent technological platforms or end up owning many of these platforms jointly or individually. It seems that banks currently enjoy an inherent advantage over potential competitors: they have much more cash to invest and can do it quickly; they have much more data that they can deploy and analyse, in addition to the public data that outside platforms may use. Finally, banks can cross-sell many more products on their online platforms relative to competing mono-product platforms. This would predict a combination of many niche firms and even larger banks. However, banks are run with legacy computer systems, are highly regulated, and, much like any large enterprise, may be slow to adopt new platforms that partially cannibalise their existing businesses. This gives an edge to small and nimble outsiders that have nothing to lose.

Another interesting case involves doing business in developing countries, where missing institutions make it harder to use markets to the same extent that they are used in more developed countries, as local well-connected corporations prevent competition. Technology that overcomes some of the missing institutions may become 
much more important in promoting market activity in developing countries than in the developed world. Alibaba is a good example of creating a huge market activity and so is the rapid spread of mobile payment systems in Africa. Blockchain technology - recording real-time data on transactions among individuals and firms in a secure, permanent, and immutable manner - and its diffusion in emerging markets, can reduce corruption, eliminate costly local intermediaries, and build trust between firms and customers regardless of their origin. Automation and the introduction of smart contacts can further enhance trust and lower transaction costs by eliminating powerful intermediaries. Put differently, blockchain technology has the potential to replace missing market institutions in emerging economies, leading to significant efficiency gains. ${ }^{1}$ Conceptually, this could lead to 'institutional leapfrogging', where emerging markets will overcome their institutional voids by adopting new technologies. In such a case, the competitive advantage of domestic firms that hinges on their ability to manage the institutional frictions would be reduced, leading to intensified competition from outside firms in growing emerging markets. This is, of course, conditional on a supportive regulatory regime that does not yield to pressures to prevent the emergence of these technologies. It remains unclear, at present, whether multinational corporations, which have found it difficult to penetrate many developing countries, are going to be the winners due to their technological advantage, or whether technologically savvy smaller players within these markets will be the main beneficiaries.

\section{Changing firm boundaries}

In terms of its effect on firm boundaries, technology is predicted to enable both centrifugal and centripetal forces, where the former will be leading to the emergence of many small, even atomistic, firms while the latter will be leading to the emergence of very large corporate entities utilising, or even controlling, technology.

\footnotetext{
${ }^{1}$ It is not surprising, therefore, that blockchain applications are booming in emerging markets, initiated by both governments and private firms. In Brazil, the government is developing a blockchain Ethereum platform to run elections. This application allows the government to fight election fraud and reduce human errors in processing election results. Private sector applications are booming as well, mostly in financial services and input markets, fuelled by smart contracts aimed at building trust among buyers and sellers and removing powerful intermediaries who are often the main source of corruption that hampers efficient market transactions. In the timber industry, for example, the Brazilian company BVRio applies Ethereum technology to record information on the origin of timber and to use smart contracts to automatically authenticate and govern timber shipment transactions. The South African company Wala is using the Ethereum platform to develop a new digital banking model to bring accessible, zero-fee banking to the sub-Saharan Africa population by using a mobile biometric customer authentication system to identify and keep track of clients.
} 
A key attribute of information technology is that it has the potential to reduce the inhibiting effects of geographic distance (Jaffe et al. 1993), allowing distant entities to interact more efficiently. It is a relatively new process that has intensified in the last decade. As was pointed out earlier, the same technology reduces inter-organisational frictions, although this process has been evolving over several decades; thus its potential is probably more limited (Aghion et al. 2017).

If technology allows geographically and organisationally distant individuals and organisations to interact more efficiently (that is, reduces distance-based transaction costs), we may see new ways of organising business. For example, many small distant firms or even individuals with complementary products or services may act in sort of 'federations' that will disrupt the existing global value chains (Gereffi et al. 2005) and employ crowdsourcing platforms to establish reputations.

At the same time, technology may also have the opposite effect, facilitating the emergence of very large corporations that make the best use of technology. While most companies feel threatened by technologies and are constantly looking for ways to counter tech-based threats, those that will adapt their business to incorporate the technology to their advantage will grow at the expense of those that cannot. The most extreme example is the emergence of the giant online platforms.

\section{Online two-way platforms}

Online two-way platforms (Google, Facebook, Amazon, and the like) extract usergenerated data through the consumption of some free service they grant, and then create a set of products and services to sell to the other side of the platform, typically advertisers or product/service providers. The corporations that run two-way platforms already possess the advantage of controlling large amounts of data and enjoy strong network effects due to their dominance in specific areas (such as online search, social networks, or online retail). Coupled together, the possession of rich personalised data and market dominance grants such two-way platforms significant competitive advantages in terms of market power, the ability to discriminate on prices (using their rich data which grant them unprecedented knowledge on consumers' willingness to pay), and the ability to lock in their customers (due to the superior network effects they can offer). These features generate a potential 'winner-takes-all' outcome associated with rapidly declining competition, which is apparently already becoming a widespread phenomenon, as documented in Grullon et al. (2017). They find that concentration and profitability have increased significantly in the US in the last several decades and suggest that this trend may be due to technological advantages and possibly also due to reduced antitrust enforcement. ${ }^{2}$

${ }^{2}$ Grullon et al. (2017) show that, in the last fifteen years, larger companies have owned more patents in general, and the more profitable ones in particular, cementing their technological lead. 
In terms of their possible effects on their industry and corporate structure, the two-way platforms may differ from other large corporations today and in the past in at least three ways:

1. Economies of scale are much more pronounced in two-way platforms due to their close to zero marginal cost of generating, storing, and analysing data. These can be compared to the economies of scale of telephone companies when switch stations became electronic, enabling them to add customers at very low marginal cost. This implies that industries disrupted by these technologies will see a decline in prices (in telecom, prices have already gone down by over 90 per cent in recent years), forcing more traditional competitors to follow suit, reducing labour costs and introducing new technologies.

2. Most companies wishing to distribute their goods and services online must use one or more platforms. These platforms are proprietary and can deny services to anyone at will. If a firm is successful, its dependence on the platform is absolute. In principle, therefore, the corporate owner of the platform holds call options on any company that operates on the platform, given the threat to limit their operations or even shut them down. Accordingly, some of the more successful firms have voiced complaints and are considering alternative ways to be present online.

3. Unlike in the past, giant platforms can acquire their potential future competitors at a time when these are not considered part of the same industry based on the standard market definitions, thus not subject to antitrust legislation. Grullon et al. (2017) argue that antitrust enforcement is already weakening, at least in the United States, a feature which only reinforces the trend.

There is some indication that public opinion is turning against the online giants that were perceived as knights in shining armour only a few years ago. It seems that, while they cannot afford not to grow due to stronger competition, at some point their size will turn against them - they will become 'too big to exist' and drastic regulatory measures may be applied to them. This has been done many times in history. It would be hard to do this within the standard antitrust economic and legal framework; thus, a new format will likely be developed to regulate online commerce, social networks, and other platforms which collect enormous amounts of public data almost for free. Furman and Seaman (2018) argue that a specific AI regulator will be necessary, possibly as part of the new doctrine. We return to this issue below.

Two-way platforms exhibit a much higher revenue-per-employee ratio than more traditional firms (Arrieta-Ibarra et al. 2018). One of the reasons for this difference is

Van Reenen (2018) argues that many industries have become 'winner takes most/all' due to globalisation and new technologies, not because of relaxed antitrust rules or rising regulation. 
that two-way platforms utilise their end-users, who function as virtually wage-free labour creating 'raw material'- the personalised data. Combined with the platform owners' capital investments (technology), this creates sellable products and services. This trend may intensify due to large amounts of user-generated data associated with the spread of the Internet of Things.

The increasing reliance of platforms on a model of free labour that generates data may lead to a fundamental transformation of employment as we currently know it, exacerbating the disruptions to the labour market discussed before. The process is likely to intensify: Dube et al. (2017) and Arrieta-Ibarra et al. (2018) show that the size and dominance of the digital platforms in their respective markets award them a significant monopsony power, which will become stronger as they grow. It is almost impossible to compete with a monopsony facing almost zero labour costs and strong economies of scale in technology.

As was stated earlier, these platforms also facilitate the emergence of decentralised labour markets for a variety of tasks - programming-related or otherwise-further complicating the labour-market landscape, as people with the necessary skills around the world will be able to work anywhere without obtaining a visa, and will have vastly different opportunities relative to other workers in the same country. An evolving example is the cottage industry of software developers in Ukraine and Belarus, working for tech companies in Israel and other countries with a high demand for developers, earning much higher salaries than their peers with comparable education levels. Amazon's MTurk is another example of a platform on which individuals from around the world perform specific digital tasks and get paid (Dube et al. 2018).

Given that personalised data can be considered as another way of generating a valuable input into the business models of digital two-way platforms (Posner \& Weyl 2018), it is possible that, at some point, this activity will generate markets that will compensate people who generate their data. Governments may be interested in facilitating this process, especially for firms that are not in their territory and are therefore difficult to tax. The recent European Union General Data Protection Regulation (GDPR) already states that user-generated personalised data are an intellectual property of the users, who should have the right to transfer them between platforms as well as to remove their data from all platforms. Given such rights, it may be possible to monetise the use of user-generated personal data, as is done with music and other copyrighted materials.

This scenario is not likely to generate large compensation per person, as the value of one individual's data is of little value in a big-data context. At an aggregate level, however, this will constitute a large cost for the platforms and may invalidate their current business model. Therefore, they are unlikely to go along with this, to say the least. If pushed, they may offer customers two modes of engagement - sharing data 
for free and enjoying free services, or getting paid for the data and paying for services. Given the observed behaviour of users of these platforms, it seems unlikely that many people will bother to get paid a small amount and start signing contracts and paying for every service they currently consume online for free. As an illustration, consider that today, under the existing regulations in many countries, any individual may restrict the use of their data by changing parameters in their account. The majority of users never bother. However, another scenario is also possible. Paying for data generated by users could, somewhat counterintuitively, reduce the extent of competition faced by tech giants, as most of the small players in fintech, digital health, and other fields whose business models rely on mining data for free may go out of business. An equilibrium with payment for every piece of data may well end up reducing competition from these small players and benefitting the tech giants.

\section{Technology-assisted governance contracts}

Some of the new technologies, such as machine learning, may assist the governance of corporations. These technologies can significantly reduce the cost of monitoring agents (managers) by principals (shareholders and regulators), which may have far-reaching implications for the corporate governance and the regulation of public corporations. The two main features which may be affected by new technologies are the ability to monitor agents and the ability to process information in order to make better predictions.

AI algorithms may become better on average at making governance decisions than individuals due to their superior ability to process information, freedom from biases, and lack of side interests. Bebchuk and Fried (2003, 2004), among others, claim that managers capture boards, which no longer monitor management but still pay top executives handsomely. Moreover, board members are frequently chosen due to their personal connections rather than their potential contribution to the corporation. A recent working paper by Erel et al. (2018) proposes a new method of nominating directors based on a machine learning algorithm and shows that the proposed directors subsequently outperform a sample of serving directors. Similar methods can be used to identify candidates for the CEO position and other senior positions, overcoming organisational politics and favoritism. Similarly, compensation structures and bonuses can be determined by smart contracts that are set in advance and require no ex post discussion, have no personal commitments, and act to the benefit of shareholders.

AI algorithms are already used to identify better performing companies through analyses of vast amounts of information about the company, its markets, competitors, customers, and the overall economy. Such algorithms can incorporate thousands 
of data series in real time and they are getting much better at it, reducing the need for human analysts to struggle with huge amounts of corporate disclosures.

These two features - the improved ability to monitor agents and the improved ability to process information - can lead to two important developments that could, in principle, change corporate and securities laws.

1. The modern public company board has two principal tasks: to monitor management and to set the company's strategy. Suppose a board uses algorithms (if consistent with its fiduciary duties) to perform all its major monitoring functions, decisions such as nominating board members, selecting a CEO or ending his or her term, setting executive pay arrangements, and approving major corporate decisions. Then, the monitoring role of such a board would basically be reduced to the choice of algorithms. At the same time, the board could devote more of its limited time to corporate strategy. This could lead to dramatic changes in board composition-fewer accounting experts, for example, and more members with significant business experience and expertise. More generally, as the task of containing managerial agency costs is left to algorithms, much of corporate governance should focus on evaluating management's vision and ability to generate above-market returns (Goshen \& Hamdani 2017). In fact, if all companies were run this way, much of corporate law and investor protection, especially where they touch on public corporations, would focus only on ensuring the quality of algorithms. Approval of algorithms will reduce the amount of litigation that accompanies many board decisions, as algorithms have no discretion. This may sound like science fiction, but, in fact, it is beginning to take place in other areas of law. To begin, regulators can allow this process to move forward by requiring, for example, the board to report to shareholders if it decides not to choose the candidate proposed by its own algorithm.

2. A similar transformation may be on its way to the mandatory reporting of financial and other information by public companies. Securities regulations around the world today require the reporting of large amounts of information to investors, which is way too much and at the same time possibly not enough. It is too much, as reporting this information is costly, and it is mostly lost on the very investors it is supposed to protect - the small ones. It makes listing prohibitively costly for even medium-sized companies. At the same time, since this information becomes public, the firm cannot disclose any sensitive information; hence much information is never disclosed. AI algorithms create an environment that, in principle, allows the disclosure of much more information without jeopardising the firm's competitive position. Regulators can 
adopt the model of credit rating agencies, obtaining confidential access to most information from the company, deploying AI on this information and auxiliary data, and then reporting only a set of pre-determined variables that can help investors make decisions. There would be no concern any more about information overload, and no need for notoriously vague concepts such as 'material information'. As before, the regulation will be focussed on approval of the relevant algorithms.

3. The regulatory process of approving algorithms is a new concept and would require a novel conceptual framework. As algorithms become more and more complex, they would need to be tested to ensure not only good performance on average, but also a very high standard of resilience to pathological cases. Lessons can be learned from the drug approval process which has similar characteristics, to some extent. And much like the prohibition on using prescription drugs without the approval of a trained and certified professional, it may be wise to mandate that small unsophisticated investors be encouraged (allowed) to invest directly in the stock market only through an algorithmassisted process.

4. Simplifying regulation in this manner will allow many more firms (small and medium) to enter the public markets, as it will reduce the cost and the complexity of regulation.

\section{Technology and corporate ownership}

Google is not only one of the early 'platform' companies; it also set an important precedent when it went public in 2004 with a dual-class share structure. The dual-class share structure allows entrepreneurs to control the corporation without owning a majority of cash flow rights. This controversial ownership structure existed long before Google went public. Yet, since the IPO (initial public offering) of Google, many prominent technology companies, such as Facebook, Alibaba, Snap, and Dropbox, have gone public with a differential voting structure that secures the founders' uncontested control over the corporation. This governance structure has become so popular among technology companies that both the Hong Kong and the Singapore stock exchanges have recently changed their listing rules to allow technology companies with differential voting structures to list their shares for trading (a feature hitherto prohibited).

These developments call for research on the link between technological change and corporate ownership. Conventional wisdom suggests that dual-class and other multiple voting structures allow companies to focus on the long term. This explanation, 
however, is unlikely to apply to companies whose investors commonly buy their shares not because of their current earnings, but because of their promise of exponential future growth. It may be the case that in an era of rapid technological change both investors and entrepreneurs care enough about the ability of company founders to pursue their own vision for disrupting incumbents (Goshen \& Hamdani 2017). This, in turn, requires founders to secure their control, thereby allowing them to pursue their own vision, even when markets and investors do not necessarily agree with the company's strategic direction.

\section{Supply chain contracts}

Finally, there is little doubt that supply chains are being disrupted by technology and that new marketplaces are arising, circumventing the informational advantage of incumbents and making efficient supply chains accessible even to small companies. Examples are too numerous and too diverse to do justice to this topic. Future research will have to shed light on the ways in which various technologies alter, complicate, or reinforce various corporate contracts, and evaluate the net effects of these influences on the corporation.

\section{Research questions on firm boundaries and corporate governance}

- What is the extent of the effect of the above-mentioned technologies on transaction costs inside corporations and in the market? Are online giants different from the 'robber barons' of old? From the public utilities in the 1930s? From AT\&T in the 1970-80s?

- To what degree do the above technologies lead to the growth of non-standard employment modes, such as more part-time work, temporary contracts, and self-employment?

- To what extent can giant two-way platforms be competitively threatened?

- What is the extent of the increase in the premium for skills that cannot be replaced by robots and AI: namely, cognitive skills such as creativity, critical thinking, and socio-emotional skills? What percentage of the population can be taught these skills?

- What is the market structure in an equilibrium where individuals can be differentially compensated for their personalised data based on their quality? Does an equilibrium exist, given the fact that a single individual's data are of very little value? What would be the equilibrium where platforms offer two modes of consuming its products, free with free access to your data, or paid access with payment for data? 
- What is a possible regulatory framework for algorithms? How would one test such a framework?

\section{POLICY, TRUST, AND OTHER SOCIAL ISSUES AFFECTING THE CORPORATION}

Trust and social cohesion are directly affected by technology, an issue which is outside the scope of this paper, but they are also affected by the way corporations adopt and use technology, which is central to the present discussion. In fact, it is the erosion of trust in corporations and in technology that, in our opinion, may be the single most dramatic factor affecting the corporate future. There are a few distinct venues, internal to the corporation and external, through which this can happen-we present a few of them below:

- Large corporations are becoming more and more global, and relying more and more on decentralised work - out of home, remote locations, across different time zones. This is made possible by technology, but it also reduces the social cohesion within the corporation.

- Massive displacement of workers associated with technology adoption further reduces the internal cohesion of the corporation. It also reduces loyalty and, as a result, younger workers exhibit much higher turnover than before. This raises the costs of human resource management, prompting an even higher reliance on technology to achieve ever-increasing efficiency.

- Large corporations in general have always been the target of suspicion, but as they grow and become less national champions, distrust in them seems to become even more pronounced. This is compounded by the pro-environmental movement, the anti-globalisation movement, unhappiness about higher costs of living, and the rapidly emerging privacy concerns which are especially relevant for companies holding large amounts of personal data.

In this section we look first at the history of technological and business upheavals, and then discuss the possible effects of some of these issues on corporations.

\section{Cycles of innovation, monopoly power, and regulation}

It is perhaps natural to begin this discussion by considering some historical parallels to the recent rise of large corporations using novel technology leading to monopoly power, public outrage, and new regulation. 
In the late 19th century, 'robber barons' dominated many of the modern sectors of the US economy. Railroads, steel, the nascent oil industry, shipping, and other sectors were controlled by successful wealthy entrepreneurs, such as Rockefeller, Carnegie, Vanderbilt, Morgan, and others. The firms controlled by these entrepreneursbusinessmen accumulated monopoly power as a result of their ability to implement and deploy new technology. They competed fiercely against actual and potential rivals, unimpeded by regulation or any other rules of the game, which did not exist at the time (e.g., Morris 2005).

The public discourse, starting in the 1880s, came to view the power exercised by the 'robber barons' (a derogatory term, apparently first used in the New York Times in 1882 (see Tipple 1959)) as a menace. This was partly driven by farmers' resentment of high rail freight fares, but also by wider (and deeper, with historical origins) concerns about monopoly power (Letwin 1965). Because of the dramatic technological progress in rail transport and other sectors, which could have led to a fall in prices, companies may have had powerful incentives to collude, further exacerbating public concerns (McCraw 1981). The Sherman Act of 1890 and the Clayton Act of 1914 were passed by presidents concerned about the threat posed by big business to the power of the government (specific concerns existed with respect to Standard Oil and US Steel). It was originally used to break up 'trust' arrangements, which were intricate schemes to coordinate the actions of firms whose shares were held through voting trusts. However, the Acts eventually proscribed anti-competitive practices more generally, not just literal 'trusts', and the term became synonymous with anticompetitive behaviour. ${ }^{3}$

The nascent limitations on anti-competitive practices introduced around the turn of the 20th century did not preclude the formation of a new type of corporate empire: pyramidal groups controlled through holding companies to which existing antitrust tools did not apply. Kandel et al. (2018) describe this process in detail; holding companies first became legal in New Jersey in 1888 and then other 'competing' States followed and legalised the holding company organisational form. Of special interest for the discussion here are public utilities (PU) groups/holding companies: Much like the rise of railroads and others monopolies in the 19th century, the rise of PU groups was related to the rise of new (network) technologies, telephone, telegraph, electricity, etc. and the multiple potential uses of the new infrastructure: Electrification was the Internet of the 1920s; electric power poles could double as telephone poles, allowing giants like AT\&T to monopolise the telephone business by the late $1920 \mathrm{~s} .{ }^{4} \mathrm{Kandel}$

\footnotetext{
${ }^{3}$ Although US competition laws have some roots in British common law, modern competition (antitrust) policy did not exist in the UK (or anywhere else) until after World War 2.

${ }^{4}$ Jovanovic and Rousseau (2003) compare certain aspects of dot.com stock price behaviour with the
} 
et al. (2018) describe how the PU sector was dominated by groups/holding companies which were, to a large extent, outside the scope of existing regulatory mechanisms. ${ }^{5}$

As pyramidal business groups in general, and PU groups in particular, accumulated economic power, and the trauma of the Great Depression set in, the public discourse about them became hostile (especially after the collapse the Insull group in 1932). President Roosevelt, echoing the anti-big-business concerns of the turn of the 20th century, regarded the monopoly and political power associated with powerful holding companies as a menace (Roosevelt 1942).

Once again, much like in the late 19th century, the existing regulatory tools were deemed inadequate or insufficient. Antitrust regulation, in particular, was underfunded and not effective against the new threats in the 1930s (Kandel et al. 2018). Hence, new regulatory tools had to be invented to deal with the business group/ holding company form of monopoly power. The Public Utilities Holding Company Act (PUHCA) targeted PU groups and, together with other new regulatory tools (the intercorporate dividend tax, increased estate taxes etc. (see Kandel et al. 2018)), eventually brought about the virtual elimination of the business group corporate form in the US by 1950.

The historical discussion here raises the possibility that the tech giants of the 21st century may follow a similar path. The parallels are economic (and political) power emanating from the new technology and rising public concern. As in previous historical episodes, the standard regulatory arsenal of antitrust tools seems inadequate for dealing with this type of economic power: price-cost margins are not well defined; 'markets', where standard (Herfindahl) or other measures of concentration can be calculated, are also not well defined; and the worldwide operations of the tech giants and their potential for regulatory arbitrage make it very difficult to impose any rules/ regulations unless they are applied across countries. ${ }^{6}$ Just as antitrust tools were invented to deal with the monopoly power of the 19th-century 'robber barons' and the PUHCA, the intercorporate tax and other regulatory tools were designed specifically to deal with US pyramids of the 1930s, we expect that political pressure will mount and will lead to a new set of regulatory tools, perhaps even coordinated across borders, to deal with the power of present-day tech giants. The challenge is the formation of a

\footnotetext{
behaviour of electricity-related companies in the first third of the 20th century. Wu (2010), who describes the history of Bell/AT\&T during the 20th century, also alludes to cycles of innovation in telephony and subsequent monopoly power, some of which took place during the 1920s and 1930s.

${ }^{5}$ The distinction between the business groups and holding companies and their affiliates that do not constitute a group - which is based on the number public companies under common control (see Kandel et al. 2018)_-does not matter for the present discussion.

${ }^{6}$ In a recent article, Khan (2016) describes in considerable detail why the standard ('Chicago') tools of antitrust analysis are insufficient for addressing the market power of Amazon and other tech giants.
} 
conceptual basis, and subsequently also a detailed plan, of how the new regulatory tools must work so as to prevent the abuse of excessive economic power, while at the same time not stopping technological progress. Possible directions for new regulation could include, for example, attempts to limit the tech giants' monopsony power vis-àvis the providers of data, new requirements for transparency, limitations on certain uses and applications of data, and many more.

\section{Two disconnected economies}

Skill-biased technological change has been in the lexicon of economists and other social scientists for a long time. However, it seems that the process is only intensifying as technological changes are becoming more drastic and more frequent; thus the resulting effect on the labour market and the overall economy is becoming more pronounced.

Israel is an interesting example, as its technologically innovative economy is the largest in the world in terms of technology-related economic activity as a percentage of GDP (12.4 per cent) and as a percentage of total employment (8.3 per cent). Over time, we observe a process of bifurcation, leading to the current state where the technologically innovative economy and the traditional economy are basically disconnected. They require differently skilled people, different financing instruments, different knowledge bases, and different regulatory environments. The innovative economy is very mobile, and so countries compete for its companies and people, creating favourable conditions and reducing taxes and regulation.

While for now the 'technological innovation hub' is a dream of many politicians, and geeks are considered 'cool' in the public discourse, the continuing disconnect between the environment in which they operate and the rest of the economy jeopardises further development of this field. First, apart from using the technology, the public does not feel the benefits of having this technology developed in their country - especially in a small country like Israel, where most of the technology is exported. Moreover, the technologically innovative economy is focussed on disrupting the traditional economy, which, in many cases, means displacing workers-mainly white-collar, middle-class jobs in the service sector. This is a serious social issue, especially in larger countries. In some countries, this has already led to a backlash: labour unions and some voters increasingly associate the very term 'innovation' with job losses, causing some politicians to stop using this term.

Displaced middle-class workers in the service sector are less likely to find a job in the technology sector and therefore, in many cases, will have to settle for a much lower paying job. At the same time, given the shortage of skilled labour facing the technologically innovative economies around the world, the significantly higher wages (and 
options awards) in this industry continue to rise. These two factors contribute to a continuous rise in income and wealth inequality.

Continuous disconnect, accompanied by an increase in inequality, is likely to bring intensifying political pressure to tax and regulate the technology companies and, as a by-product, will add pressure on the giant online platforms discussed above.

\section{Taxation}

Can governments address this issue? They can easily reduce the budgetary support for innovation and tax it more, so as to free funds for various transfer payments designed to reduce inequality. Recall, however, that technological corporations and their employees are very much in demand all over the world; thus many will search for the least onerous tax environments and the maximal support. In the absence of tax harmonisation, this will only continue the race to the bottom, as some countries will cater to company needs to attract them. Thus, politicians will face the following dilemma: attract innovation, which provides (dwindling) tax revenues, and face the anger of most of the population, or adopt more populist measures and lose future economic growth. It seems that, at some point, the developed countries will understand that they cannot win the war to attract technology companies and employees and must therefore collaborate, perhaps by adopting a more coherent and harmonised corporate tax code that shares the value generated from the intellectual property (IP) of these companies in some reasonable way. While some attempts are being made in this direction (for example, Base Erosion and Profit Shifting, or BEPS, the OECD's proposed way to tax IP revenues), there is no consensus on this matter.

The above, together with the remnants of the 2008 financial crisis, continue to erode the public trust in corporations and the government's ability to deal with them. Some technology, as we have seen in recent elections, may be used to reduce such trust even more. This may lead to social unrest and exert pressure on the governments to take aggressive measures. Some of them may be tempted to do so.

\section{Research questions on policy, trust, and other social issues}

- Can an analysis of newspaper articles, historical and contemporary, be used to gauge public sentiment towards large firms and place the current backlash against the tech giants in a comparative perspective?

- What would be considered 'too large to exist' for a single firm/conglomerate? 2 per cent of the economy? 5 per cent? Does it depend on the industry? Samsung constitutes 15 per cent of the world's eleventh largest economy; what 
about the online giants, which are valued more than the GDPs of most economies?

- History shows that even large dominant firms can be challenged or disrupted. Do some of the disruptive technologies (for example, blockchain) really challenge the online giants or do they make them even more invincible?

- What are the economic and legal frameworks that can be used for the treatment of a large company that does not violate the traditional antitrust laws, but keeps growing to 'dangerous' size and influence? Historically, this has led to the introduction of new regulatory tools, including antitrust legislation itself. What are the suitable new tools?

- What percentage of increased inequality can be attributed to the technological change?

\section{THE FUTURE OF THE CORPORATION}

\section{The corporation as a legal entity—must it change?}

As we have indicated, the extant theory that incorporates the above-mentioned technologies into existing economic models does not seem to predict major changes in the basic structure of the economy, including the nature of the corporation, even if these technologies are likely to affect the size and the scope of many corporations, their internal functions and operating procedures, and the way they are financed and governed. So far, there is little to indicate an expected fundamental change in the corporate legal form. Tirole (2016) outlines what he believes are the effects of AI on firms. According to him, AI is likely to increase the wage gap between skilled and unskilled labour, as the latter is presumably more substitutable with AI than the former; AI will allow firms to automate and dispense with middle-men performing monitoring tasks, flattening the firms and increasing the span of control; and AI will encourage self-employment by making it easier for individuals to build a reputation. Tirole (2016) does not seem to predict, however, that AI adoption will result in the replacement of large integrated firms by individuals loosely affiliated through various platforms. He claims that many corporate activities require large fixed or sunk costs that cannot be borne by a single individual and are hard to coordinate among many individuals. Moreover, many activities entail high risks that cannot be borne by a single agent and are hard to enforce among many agents outside of the corporate form. Aghion et al. (2017) add that all these technologies will not be able to eradicate contractual incompleteness; thus a corporate structure that allows incomplete contracts to be resolved within it is likely to remain. They also argue that AI and 
crowdsourcing help develop and maintain individual reputations, which is only relevant for some industries, but not for many others. At present, it is not clear whether viable alternatives to the corporate form will emerge and if so, what they will look like.

\section{Continued eclipse of the public corporation?}

What does this mean for the future of public corporations? Will they become a rare exception, seen only in very large companies? Will both public and private corporations survive, given that entrepreneurs can raise capital in places other than public markets?

A public corporation is subject to costly regulation, aimed primarily at protecting unsophisticated investors. This has been the reason for the regulation of public markets since the 1930s and is the rationale for the more recently imposed constraints on equity crowdfunding. Regulation includes extensive disclosure requirements which, over time, have become more and more intrusive, as public protection and anticorporate sentiments became much more pronounced following the crises of 2000 and 2008. The decision to become a public corporation is the result of weighing the benefits (liquidity, access to capital, price discovery, that can help motivate employees and the ability of the founders to diversify their holdings) against the cost of listing, disclosure, litigation, and regulation.

Technology is likely to alter the cost-benefit analysis of taking a company public. On the benefit side, technology and financial innovation offer a significant new supply of capital for private companies from three sources: (a) private equity funds, endowments, and sovereign wealth funds that now rival in size the public markets and are not only comfortable with investing in private companies over long horizons, but may actually prefer to stay away from the public markets; (b) small investors, often aided by new technologies, have access to instruments that allow them to invest in private companies, both in equity and debt contracts; (c) institutional trading platforms that used to focus on public markets now offer technological platforms that allow firms to stay private, yet obtain financing directly from institutional investors. This means that the access to public capital markets is no longer the main game in town, which may explain the reduction in the number of IPOs in recent years. New platforms for secondary trading in private company shares allow early investors and employees to liquidate their holdings without the company going public; diversification and liquidity reasons are also less important. Finally, some argue that algorithms based on big data may outperform the market price mechanism as a source of information for evaluating companies and their management (Mayer-Schonberger \& Ramge 2018). 
On the cost side, as discussed earlier, technology, supported by smart regulation, can significantly reduce the agency costs associated with raising capital from a dispersed group of unsophisticated investors. Unless regulators take the opportunity to embrace technology and drastically change the way public companies are regulated, it seems plausible that the continuous drive for higher protection of small investors will further reduce the importance of public markets.

\section{Research questions on the future of the corporation}

- What are the competing corporate forms, and what is the extent of their success in certain industries? Is there a positive model explaining such success?

- Is it possible to identify the main reasons for the decline of IPOs in the developed countries? Is it likely to continue?

\section{SUMMARY AND POLICY IMPLICATIONS}

Unlike most academic research in economics, strategy, and law, this project is an attempt to predict the future not on the basis of a mathematical model, but rather in a much more holistic way. This is an inherently speculative task, which we have approached by compiling a diverse list of arguments from a variety of fields, hoping to outline directions in which the future of the corporation can evolve and perhaps offer some insights. In this section we try to draw a few conclusions and suggest reasonable steps that governments and corporates can take to be more prepared for this potentially turbulent future.

Two messages that clearly come out of the academic and business literatures described above are that:

1. The wave of new technologies is likely to be more disruptive than its predecessors. We have little understanding of how these new technologies will affect current business models; they are likely to have many effects, some reinforcing each other, others opposing. There is definitely a wide range of opinions about the scope and the pace of this change.

2. These technologies will generate many drastic and rapid changes, resulting in a large degree of uncertainty regarding the new business models, regulatory environment, social norms, and our day-to-day behaviour.

What are the changes in corporate structure and mode of operations that are likely to stem from technological changes? 
It is unlikely that the basic corporate form will change, since, at present, no alternative mechanism exists for sharing risks in large projects and for coordinating them across many functions, while maintaining a single responsibility. Iansiti and Lakhani (2017) argue that blockchain technology, but it has the potential to seriously disrupt the very nature of the corporation by decentralising it, is two decades away in terms of its ability to do so on a large scale.

We also do not think that it is possible to predict the effect of technology on the scope and size of corporations in general, as they depend on the specific changes to the costs and benefits of using markets relative to in-house activities brought about by these technologies. In some cases, firms will become much larger while in others they will probably shrink and perhaps wither, replaced by loose coalitions of smaller companies around the supply chain, that can coordinate much more easily than before using technology.

At the same time, unless the regulatory regime changes and takes advantage of the same technologies that cause corporations to reduce reliance on public markets, the future of public corporations may not be very bright. Much stronger competition from alternative sources of capital with longer horizons, combined with the ability of small companies to access and analyse data in ways available previously only to very large companies, may precipitate the eclipse of the public corporation. To save the public markets, regulators must reduce transaction costs at all levels, while at the same time providing an even better (smarter) protection to investors. Only advanced technology can allow this.

We have shown that technological innovation has negative side effects that are relevant for the future of the corporation: it may cause upheavals in labour markets, create high inequality in a bifurcated economy, and generate giant companies that may become increasingly distrusted by both the public and governments. New market or regulatory paradigms need to be developed to address these negative effects, including internationally harmonised taxation and capabilities to regulate algorithms and to deal with online giants that do not fall under the standard antitrust legislation. In the absence of these steps, which should be designed ahead of time and in wide consultation with experts, popular frustration may bring about bad regulation attempting to quickly placate the public.

We have posed many research questions that could be of interest for anyone trying to predict the evolution of technological change and its effects. We hope that researchers around the world will address some of these issues, and that governments will facilitate this process through directed grants, especially in the completely novel area of regulating algorithms. 
Finally, we would like to make a more general statement, almost a cliché. Change and the uncertainty associated with it are scary. Regulators, given their incentives, are especially wary of these, in addition to being 'behind the market' in accepting that the change has occurred, realising its extent, and understanding the technology. In the meantime, risk-averse regulators try to minimise the change and the uncertainty in their domains, which in many cases amplifies the uncertainty in the market. Many corporate boards also resist change for a variety of reasons. The question is whether we, as a society, individuals, and firms, can afford this behaviour. We do not know the answer to this from the point of view of humanity - perhaps stopping change is better in certain areas? But given the perspective of a single company, or country, that is facing competition from many others, this is not an option. Frequently, not changing is much riskier than embracing the fact that change is continuous and that we must learn to be comfortable with uncertainty. The future of specific corporations will depend on how well their boards and officers manage the technological change. The future of the corporation as an institution may depend how well we, as a society, do that.

\section{Acknowledgements}

We are grateful for the British Academy for supporting this work. We would like to thank Colin Meyer, Henry Richards, Judy Wajcman, and Andrew Neff for their comments and suggestions that helped us improve the paper.

\section{REFERENCES}

Acemoglu, D. \& Restrepo, P. (2018), 'Artificial Intelligence, Automation and Work', working paper 18-01, Massachusetts Institute of Technology, Cambridge, MA.

Aghion, P., Jones, B. \& Jones, C. (2017), 'Artificial Intelligence and Economic Growth', working paper 23928, National Bureau of Economic Research, Cambridge, MA.

Agrawal, A., Gans, J. \& Goldfarb, A. (2018), 'Economic Policy for Artificial Intelligence', working paper 24690, National Bureau of Economic Research, Cambridge, MA.

Arrieta-Ibarra, I., Goff, A., Jimenez-Hernandez, L., Lanier, D. \& Weyl, G. (2018), 'Should We Treat Data as Labor? Moving beyond "Free", American Economic Association Papers and Proceedings, 108: 38-42. https://doi.org/10.1257/pandp.20181003

Bebchuk, L. \& Fried. J. (2003), 'Executive Compensation as an Agency Problem', Journal of Economic Perspectives, 17(3): 71-92. https://doi.org/10.1257/089533003769204362

Bebchuk, L. \& Fried, J. (2004), Pay Without Performance: The Unfulfilled Promise of Executive Compensation (Cambridge, MA, Harvard University Press).

Bloom, N., Sadun, R. \& van Reenen, J. (2014), 'The Distinct Effects of Information Technology and Communication Technology on Firm Organization', Management Science, 60: 2859-85.

https://doi.org/10.1287/mnsc.2014.2013 
Coase, R. (1937), 'The Nature of the Firm', Economica, 4(16): 386-405. https://doi.org/10.1111/j.1468-0335.1937.tb00002.x

Dube, A., Jacobs, J., Naidu, S. \& Suri, S. (2017), 'Monopsony in Online Labor Markets', working paper, Columbia University, New York.

Erel, I., Stern, L., Tan, C. \& Weisbach, M. (2018), 'Selecting Directors Using Machine Learning', working paper 2018-05, Charles A. Dice Center for Research in Financial Economics, Columbus, OH.

Furman, J. \& Seamans, R. (2018), 'AI and the Economy', working paper 24689, National Bureau of Economic Research, Cambridge, MA https://papers.ssrn.com/sol3/papers.cfm?abstract_id=3194841

Gereffi, G., Humphrey, J. \& Sturgeon, T. (2005), 'The Governance of Global Value Chains', Review of International Political Economy, 12: 78-104.https://doi.org/10.1080/09692290500049805

Goshen, Z. \& Hamdani, A. (2016), ‘Corporate Control and Idiosyncratic Vision', Yale Law Journal, 125: $560-617$.

Grullon, G., Larkin, Y. \& Michaely, R. (2017), 'Are U.S. Industries Becoming More Concentrated?', unpublished working paper, Cornell University, Ithaca, NY.

Iansiti, M., \& Lakhani, K. R. (2017), 'The Truth About Blockchain', Harvard Business Review 95: $118-27$

Jaffe, A., Trajtenberg, M. \& Henderson, R. (1993), 'Geographic Localization of Knowledge Spillovers as Evidenced by Patent Citations', Quarterly Journal of Economics, 108: 577-98. https://doi.org/10.2307/2118401

Jovanovic, B. \& Rousseau, P. (2003), 'Two Technological Revolutions', Journal of the European Economic Association, 1(2-3): 419-28. https://doi.org/10.1162/154247603322391053

Kandel, E. \& Pearson, N. (2001), 'Flexibility versus Commitment in Personnel Management', Journal of the Japanese and International Economies, 15: 515-56.https://doi.org/10.1006/jjie.2001.0482

Kandel, E., Kosenko, K., Morck, R. \& Yafeh, Y. (2018), 'Great Pyramids of America: A Revised History of US Business Groups, Corporate Ownership and Regulation, 1926-1950', forthcoming in Strategic Management Journal. https://onlinelibrary.wiley.com/doi/10.1002/smj.2992

Khan, L. (2016), 'Amazon's Antitrust Paradox', Yale Law Journal, 126(3): 710-805.

Letwin, W. (1965), Law and Economic Policy in America: The Evolution of the Sherman Antitrust Act (Chicago, IL, University of Chicago Press).

Mayer-Schönberger, V. \& Ramge, T. (2018), Reinventing Capitalism in the Age of Big Data (New York, Basic Books).

McCraw, T. (1981), Prophets of Regulation: Charles Francis Adams, Louis D. Brandeis, James M. Landis, Alfred E. Kahn (Cambridge, MA, Harvard University Press).

Milgrom, P. \&. Tadelis, S. (2018), 'How Artificial Intelligence and Machine Learning Can Impact Market Design', working paper 24282, National Bureau of Economic Research, Cambridge, MA.

Morris, C. (2005), The Tycoons: How Andrew Carnegie, John D. Rockefeller, Jay Gould and J.P. Morgan Invented the American Supereconomy (New York, Times Books).

Nakamura, H. \& Zeira, J. (2018), 'Automation and Unemployment: Help is on the Way', discussion paper 12974, Centre for Economic Policy Research, London.

Posner, E. G. \& Weyl, E. (2018), Radical Markets: Uprooting Capitalism and Democracy for a Just Society (Princeton, NJ, Princeton University Press). https://doi.org/10.23943/9781400889457

Roosevelt, F. D. (1942), A Message from the President of the United States Transmitting Recommendations Relative to the Strengthening and Enforcement of Anti-trust Laws, American Economic Review, $32(1)$.

Tipple, J. (1959), 'The Anatomy of Prejudice: Origins of the Robber Baron Legend', Business History Review, 33: 510-23. https://doi.org/10.2307/3111612

Tirole, J. (2016), Economics for the Common Good (Princeton, NJ, Princeton University Press). 
Van Reenen, J. (2018), 'Increasing Differences Between Firms: Market Power and the Macro-economy', paper presented at the Jackson Hole Conference, 2018.

https://www.kansascityfed.org/ /media/files/publicat/sympos/2018/papersandhandouts/jh\%20 john $\% 20$ van $\% 20$ reenen $\% 20$ version $\% 2020$.pdf?la=en

Williamson, O. (1975), Markets and Hierarchies: Analysis and Antitrust Implications (New York, Free Press).

World Bank (2018), 'The Changing Nature of Work', working draft of the 2019 World Development Report, 30 April.

Wu, T. (2010), The Master Switch: The Rise and Fall of Information Empires (New York, Alfred Knopf).

Zeira, J. (1998), 'Workers, Machines, and Economic Growth', Quarterly Journal of Economics, 113: 1091-117.https://doi.org/10.1162/003355398555847

\section{Note on the authors}

Assaf Hamdani is a Law Professor at the Buchman Faculty of Law, Tel Aviv University. He holds an S.J.D. degree from Harvard Law School and an LL.B. degree from the Hebrew University. He has been a Visiting Professor at Columbia Law School, the University of Berkeley Law School, Harvard Law School, and the University of Pennsylvania Law School. His research areas are corporate law, corporate governance, and securities regulation. His research has been published in law reviews, including the Yale Law Journal, California Law Review, Columbia Law Review, and Stanford Law Review and in peer-reviewed journals, such as the Review of Finance. He chaired Israel's Committee on Institutional Investors and Capital Markets and served as a member of the Israel Securities Authority, and as an advisor to Israel's Committee on Institutional Investors' Investment in Corporate Bonds.

ahamdani@tauex.tau.ac.il

Niron Hashai is an Associate Professor at the Arison School of Business, the Interdisciplinary Center, Herzliya, Israel. His research interests include: theory of the multinational corporation, technological innovation, diversification, and growth patterns of high-technology firms. His research has been published in top strategy, management, international business and innovation journals, including: Journal of International Business Studies, Journal of Management, Research Policy, Strategic Management Journal, and Strategy Science.

nhashai@idc.ac.il

Eugene Kandel is the Emil Speyer Professor of Economics and Finance at the Hebrew University. He holds a PhD in Economics from the Graduate School of Business at the University of Chicago and was a faculty member at the University of Rochester. His research interests include financial markets and intermediaries as well as corporate governance. Kandel has published in top journals in Economics and Finance and served as the Editor of the Journal of Financial Markets. He is a member of the Center 
for the Study of Rationality at the Hebrew University and a Research Fellow of the London-based CEPR and the Brussels-based ECGI. Between 2009 and 2015 Prof. Kandel served as the Head of the National Economic Council and the Economic Advisor to the Prime Minister of Israel and was actively involved in shaping the economic policy of Israel. Since 2015 Kandel serves as the CEO of the non-profit organisation Start-up Nation Central that promotes the Israeli technological innovation ecosystem around the world and advocates strategies to help it grow.

eukand@gmail.com

Yishay Yafeh holds a PhD in Economics from Harvard University and has taught at Oxford, Montreal and the Hebrew University. He has served Vice Dean (2010-12) and Dean (2012-16) of the School of Business Administration of the Hebrew University. His research interests are financial systems and financial intermediation, the economies of East Asia, and economic and financial history. Dr Yafeh has served as advisor to the Bank of Israel, the Israel Securities Authority, and the International Monetary Fund. His research has been published in, among others, the Journal of Finance, the Quarterly Journal of Economics, the Journal of Economic Literature, the Journal of Business, and the Review of Finance. He co-authored, together with Paolo Mauro and Nathan Sussman, the book Emerging Markets and Financial Globalization (Oxford University Press, 2006). Yishay Yafeh is a Research Fellow of the Londonbased CEPR and the Brussels-based ECGI, and is associate editor of a number of scientific journals.

yishay.yafeh@huji.ac.il

To cite the article: Assaf Hamdani, Niron Hashai, Eugene Kandel and Yishay Yafeh (2018), 'Technological progress and the future of the corporation', Journal of the British Academy, 6(s1): 215-245.

DOI https://doi.org/10.5871/jba/006s 1.215

This article is licensed under a

Creative Commons Attribution-NonCommercial-NoDerivs 4.0 Unported License.

Journal of the British Academy (ISSN 2052-7217) is published by

The British Academy - the national academy for the humanities and social sciences.

10-11 Carlton House Terrace, London, SW1Y 5AH

www.britac.ac.uk 
